\title{
Design And Implementation Soft-switching MPPT SEPIC Converter Using P\&O Algorithm
}

\author{
Luki Septya $\mathrm{M}^{1, *}$, Indhana Sudiharto ${ }^{1}$, Syechu Dwitya $\mathrm{N}^{1}$, Ony Asrarul Qudsi ${ }^{1}$, Epyk Sunarno ${ }^{1}$ \\ ${ }^{1}$ Electrical Engineering Department Politeknik Elektronika Negeri Surabaya, Indonesia
}

\begin{abstract}
This paper presents details of design and implementation of Maximum Power Point Tracking (MPPT) SEPIC Converter to maximize Photovoltaic (PV) power output. Perturb and observe (P \& O) algorithm has been used as a tracking technique to determine MPPT. This algorithm are simple and efficient to determine the maximum power point (MPP). The soft-switching method will be added to the implementation of MPPT SEPIC Converter to reduce switching losses. The results show that the proposed MPPT method implementation can increase the output power of PV.
\end{abstract}

\section{Introduction}

In recent years, solar energy has gained great attention and popularity. This condition caused solar energy is considered the best solution for long-distance power applications that demand low voltage DC supplies that utilize alternative energy sources such as chargers for small electronic gadgets, laptops, uninterruptible power supply (UPS) and electric vehicles.

The solar energy sources conversion into electrical energy usually uses PV modules. Until now, PV is considered the best solution for remote area applications. PV has two major weakness, the power generated from PV is highly dependent on weather conditions and the conversion efficiency of PV systems is very low. However, the output characteristics of a non-linear PV module represent a unique operating point where there is maximum power generated in each irradiation. One common method to improve the efficiency of PV systems is develop MPPT controllers that continuously track MPP PV modules on all irradiation and temperature.

Many MPPT methods can be used to obtain optimal PV output power [1] - [6]. This adjusts to the complexity and needs of the system. Direct MPPT search methods such as Perturb and Observe (P\&O), Incremental Conductance (INC) and Hill Climbing algorithms can be applied using spontaneous PV voltage (VPV) and PV current (IPV) values to generate control signals.

This paper focuses on the $\mathrm{P} \& \mathrm{O}$ algorithm because of its advantages, for example it can be implemented in analog and digital form, does not require periodic, efficient and easy to implement [2] [3] [8]. The P \& O algorithm depend on the slope of the PV characteristic. In this paper, the SEPIC converter is used to validate the proposed P\&O MPPT algorithm. Much research has

Corresponding author: lukiseptya@gmail.com been done in this region that uses buck, boost, and buck boost converters.

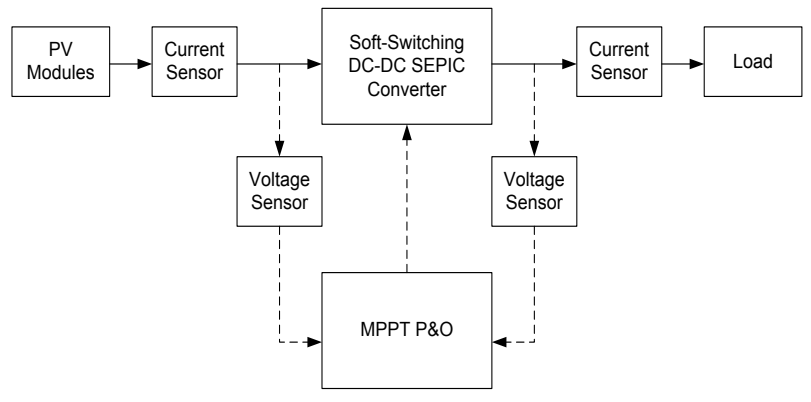

Fig. 1. Topology of soft-switching MPPT SEPIC converter

Although the boost converter is more efficient than the SEPIC converter, but the SEPIC buck-boost property makes it more adaptable [9] - [11]. In this paper we also propose soft switching on SEPIC converters that have high efficiency to improve the overall efficiency of PV systems. A Soft Switching SEPIC converter is a converter that has a non-inverted buck-boost output and has a very high efficiency.

Figure 1 shows the topology of soft switching MPPT SEPIC converter. The voltage and current of the PV output will be sensed by the voltage sensor and current sensor. These currents and voltages are used to adjust the duty cycle switching converter and are used for the MPPT P \& O algorithm. Furthermore, soft-switching DC-DC SEPIC converter as a circuit that serves to increase and decrease the voltage without changing the polarity of the resulting voltage. The output voltage sensor is used for monitoring the output voltage of the converter [12] - [14]. Then the proposed method will be compared with the conventional method so it can give an idea of the effect of using soft-switching MPPT SEPIC converter. 


\section{Design System}

In this study work has been used 6 PV modules with the capacity of each PV module is 135 WP. The PV module specifications are shown in Table 1.

Table 1. PV module specifications

\begin{tabular}{|l|l|}
\hline Maximum Power (Pm) & $135 \mathrm{WP}$ \\
\hline Open-circuit Voltage (Voc) & $61,3 \mathrm{~V}$ \\
\hline Short-circuit current (Isc) & $3,41 \mathrm{~A}$ \\
\hline Voltage at point of maximum power (Vmp) & $47 \mathrm{~V}$ \\
\hline Current at point of maximum power (Imp) & $2,88 \mathrm{~A}$ \\
\hline Modul efficiency & $9 \%$ \\
\hline Number of Cell & 45 \\
\hline $\begin{array}{l}\text { Temperature coefficient-open-circuit voltage } \\
(\alpha \text { Voc) }\end{array}$ & $-0,3$ \\
\hline $\begin{array}{l}\text { Temperature coefficient-short-circuit current } \\
(\alpha I s c)\end{array}$ & 0,07 \\
\hline Temperature coefficient-power $(\alpha$ Pm) & $-0,24$ \\
\hline
\end{tabular}

Based on the PV capacity has been used, then designed soft-switching MPPT SEPIC converter.

\subsection{Design of SEPIC converter}

In this work has been designed SEPIC converter with a capacity of 1000 Watt power. SEPIC converter can produce output voltage which can be higher or lower than input but without changing polarity. The inductor current and capacitor voltage limits are removed to investigate current and voltage fluctuations. The inductor current is assumed to work continuously on this analysis. The average inductor voltage is zero and the average capacitor current is zero for seady-state operation.

Kirchhoff's Voltage Law (KVL) on circuit Vs, L1, C1 and L2

$$
-V_{S}+V_{L 1}+V_{C 1}-V_{L 2}=0
$$

If it follows the assumption of the average voltage of the inductor, then the voltage on the capacitor $C 1$ is

$$
V_{C 1}=V_{s}
$$

When the switch is closed, the diode will be off and the circuit is shown in Figure 2.b. The transverse voltage $L 1$ for the $D T$ interfal is

$$
V_{L 1}=V_{S}
$$

When the switch is open, the diode will be on and the circuit is shown in figure 2.c. KVL on the outer path is

$$
-V_{S}+V_{L 1}+V_{C 1}+V_{O}=0
$$

The assumption of capacitor voltage $C 1$ remains constant at the mean voltage $V S$

$$
V_{L 1}=-V_{O}
$$
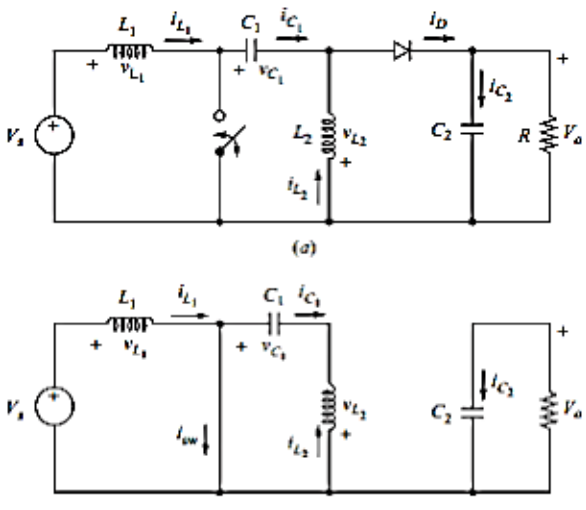

(b)

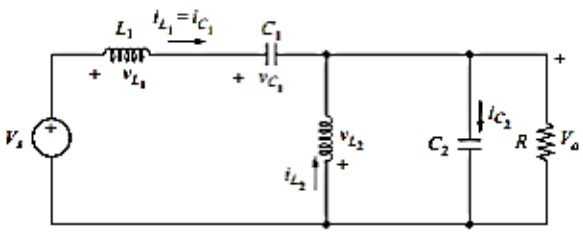

(c)

Fig. 2. (a) SEPIC circuit; (b) SEPIC circuit when switch is closed and diode off;

(c) SEPIC circuit when switch open and diode on

For intervals $(1-D) T$. Since the average inductor voltage is zero for periodic operation (steady state operation), then the equation becomes,

$$
\left(V_{S}(D T)-V_{O}(1-D) T=0\right.
$$

Where $D$ is the duty cycle ratio of the switch, ie

$$
D=\frac{V o}{V o+V s}
$$

The result of this equation is similar to buck-boost converter, with the important difference that there is no reversal polarity between the input and output voltages. The ability to have a voltage output greater or less than input without reversal polarity makes this converter suitable for many applications. The average current inductor which is also the current source can be searched by the equation:

$$
I_{L 1}=I_{S}=\frac{V_{O} I_{O}}{V_{S}}=\frac{V_{O}^{2}}{V_{S} R}
$$

The variation in $i_{L 1}$ when the closed switch can be searched from the equation,

$$
V_{L 1}=V_{S}=L 1\left(\frac{d i_{L 1}}{d t}\right)=L 1\left(\frac{\Delta i_{L 1}}{\Delta t}\right)=L 1\left(\frac{\Delta i_{L 1}}{D t}\right)
$$

Where $\Delta i_{L}$ is

$$
\Delta I_{L 1}=\frac{V s D T}{L 1}=\frac{V s D}{L 1 . f}
$$

The average current in each capacitor is zero, so the mean current in $L 2$ is,

$$
I_{L 2}=I_{O}
$$


The variation in $i_{L 2}$ is determined from the circuit when the switch is closed. Using Kirchhoff's law of KVL, C1, and $L 2$ with the voltage $C 1$ assumed Vs is constant, giving

$$
V_{L 2}=V_{C 1}=V s=L 2\left(\frac{d i_{L 2}}{d t}\right)=L 2\left(\frac{\Delta i_{L 2}}{\Delta t}\right)=L 2\left(\frac{\Delta i_{L 2}}{D T}\right)
$$

Where $\Delta i_{L 2}$ is,

$$
\Delta I_{L 2}=\frac{V s D T}{L 2}=\frac{V s D}{L 2 . f}
$$

The current waveform is shown in Figure 3. Kirchhoff KVL's Law is applied to the drawings. 3 c, assuming no ripple voltage on the capacitor, indicating that the voltage going through the switch when open is $V s$ $+V o$. From Figure $3 \mathrm{~b}$, the maximum reverse voltage of the diode bias when the diode off is also $V_{S}+V o$.

The output part consisting of diodes, $C 2$, and load resistors is the same as in boost converter, so the output of ripple voltage is,

Then $C 2$ is,

$$
\Delta V_{O}=\Delta V C s 2=\frac{V o D}{R \cdot C 2 . f}
$$

$$
C 2=\frac{D}{R\left({ }^{\Delta V o} / V o\right) f}
$$

The voltage variation in $C 1$ is determined from the shape of the circuit with the closed switch. The current capacitor $i_{C l}$ is the reciprocal of $i_{L 2}$, which has previously been determined to have an average value of Io. From the definition of capacitance and considering the magnitude of charge,

$$
\Delta V_{C 1}=\frac{\Delta Q c 1}{C}=\frac{I o \Delta t}{C}=\frac{I o D T}{C}(16)
$$

Change Io with $V o / R$,

$$
\Delta V_{C 1}=\frac{V o D}{R C 1 f}
$$

Then $C 1$ is,

$$
C 1=\frac{D}{R\left({ }^{\Delta V_{C 1} / V o}\right) f}
$$
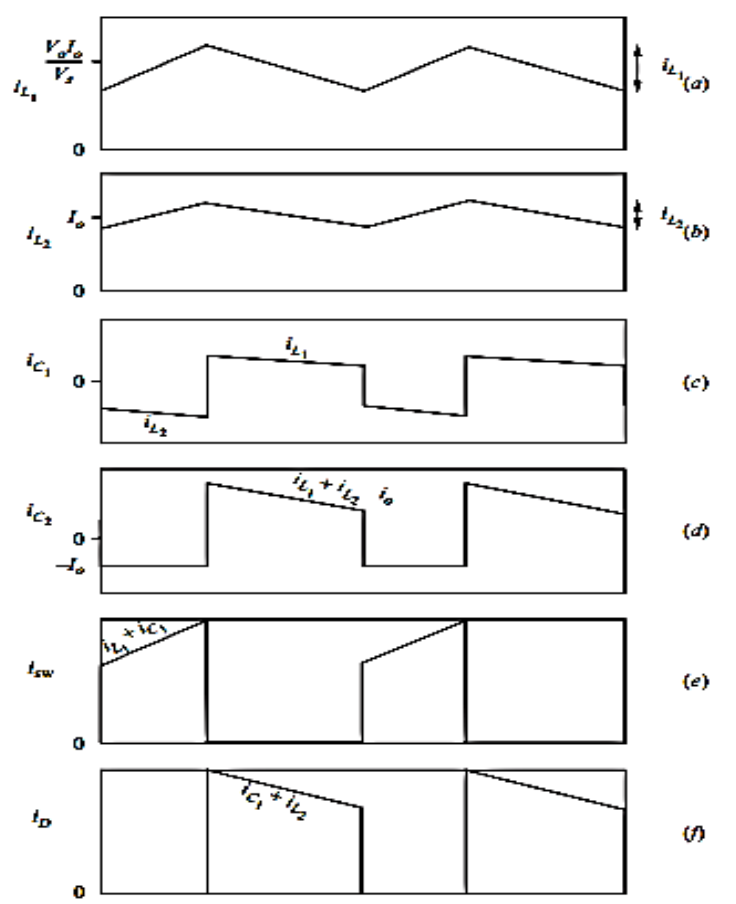

$(n)$

Fig. 3. Current of SEPIC converter. (a) L1; (b) L2; (c) C1; (d) C2; (e) switch; (f) diode

\subsection{P\&O MPPT}

The Perturb and Observe ( $\mathrm{P} \& \mathrm{O})$ algorithm is one of the simplest and easy to implement for MPPT. The design of MPPT requires two parameters to determine the slope of the control input voltage ( $\mathrm{Vin}$ ) and control input current (Iin)

$$
P_{\text {in }}(n)=V_{\text {in }}(n) x I_{\text {in }}(n)
$$

From these two parameters obtained Power (Pin), and voltage $(\mathrm{Vin})$, then compared with the previous data reading parameters that is Pin (n-1) \& Vin (n-1).

The result of comparison is obtained $\Delta P$ and $\Delta V$

$$
\begin{gathered}
\Delta V=V_{\text {in }}(n)-V_{i n}(n-1) \\
\Delta P=P_{i n}(n)-P_{i n}(n-1)
\end{gathered}
$$

And the result of division $\Delta \mathrm{P}$ and $\Delta \mathrm{V}$ will be called slope.

$$
\text { Slope }=\frac{\Delta P}{\Delta V}
$$

As in Figure 4, there are 3 types of points that are in 3 positions. To the left of the $d P / d V>0$ peak, the curve curve $d P / d V=0$ and to the right of the peak $d P / d V<0$. On the left side of the MPP the power changes to the voltage change $d P / d V>0$, while on the right, $d P / d V 0$, it is known that perturbation is done to move the PV working voltage forward MPP control. If $\mathrm{dP} / \mathrm{dV}$, then the work point change directs PV away from MPP. Then the $\mathrm{P} \& \mathrm{O}$ algorithm reverse the disturbance direction. 


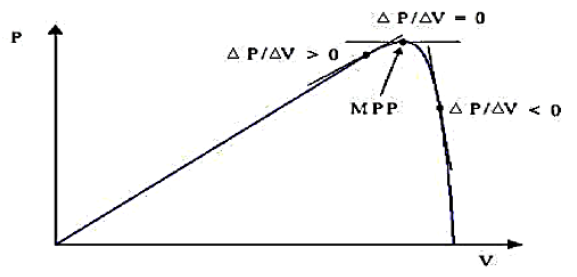

Fig. 4. Different $\Delta \mathrm{P} / \Delta \mathrm{V}$ positions on the $\mathrm{PV}$ curve

Flowchart of the $\mathrm{P} \& \mathrm{O}$ algorithm is shown in Figure 5. First of all measure or sensing voltage $\left(V_{K}\right)$ and output current $\left(I_{K}\right)$ PV. Then calculate the power with the multiplication of voltage and current of sensing result $\left(P_{K}\right)$. Furthermore, compared to the current power $\left(P_{K}\right)$ is greater than the previous power $\left(P_{K-1}\right)$, if yes then compare the current voltage $\left(V_{K}\right)$ is greater than the previous voltage $\left(V_{K-1}\right)$, if yes then naiakn Vref by raising duty Cycle on the converter. Conversely if not, then lower the Vref by lowering the duty cycle. If the current power $(\mathrm{PK})$ is not greater than the previous power $\left(P_{K-1}\right)$, then compare the current voltage $\left(V_{K}\right)$ is greater than the preceding voltage $\left(V_{K-1}\right)$, if yes then naiakn Vref by raising the duty cycle on the converter. Conversely if not, then lower the Vref by lowering the duty cycle.

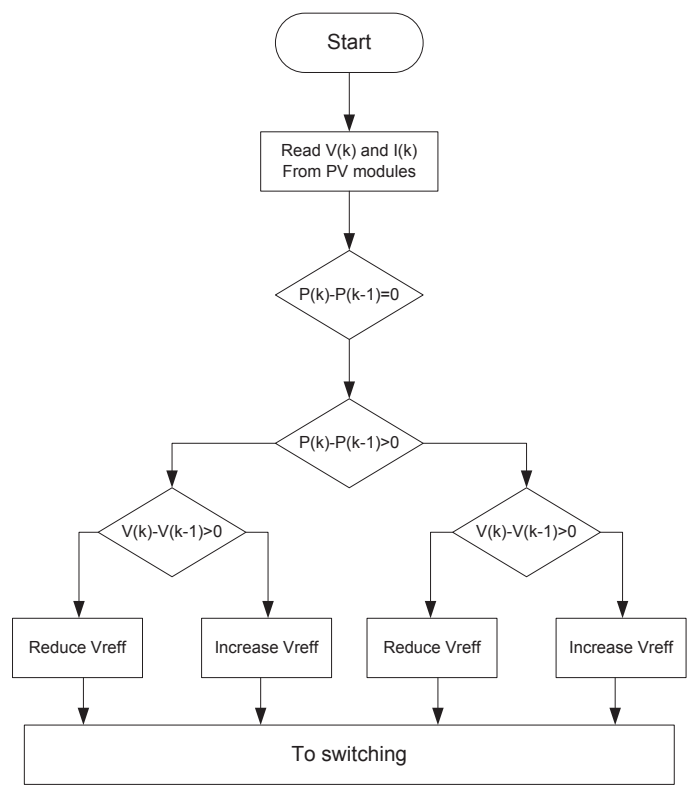

Fig. 5. Flowchart of the P \& O algorithm

\subsection{Soft-switching}

Voltage and current switching do not switch to zero instantaneously at turn-on or turn-off. There is a time duration during switching transitions (ie turn-on and turn-off switching). Power losses during switching exist in overlapping or overlapping regions of current waves and switch voltages during turn-on or turn-off. Since the average power is energy divided by the period, then the higher the switching frequency causes higher switching losses. Sharp and sudden switching transitions are also sources of electromagnetic interference (EMI) noise that can affect the performance of converters and other surrounding electrical equipment. Figure 6 shows the current and voltage graphs of switch $S 1$ during the switching cycle. At the time of the driver pulse from $S 1$ off then $S 1$ turn-off. $S 1$ takes time $t_{\text {off }}$ to completely turn off. During this time, there is an overlap of the current wave and voltage, resulting in a turn-off loss represented by the area below the $P_{\text {off }}$ graph. At $t$, the driver pulses on and switch $S 1$ will turn-on. At this time, the $S 1$ switch takes $t_{o n}$ of time for turn on. During this time, there is an overlap of current wave and voltage from $S 1$, so the turn on losses occur.

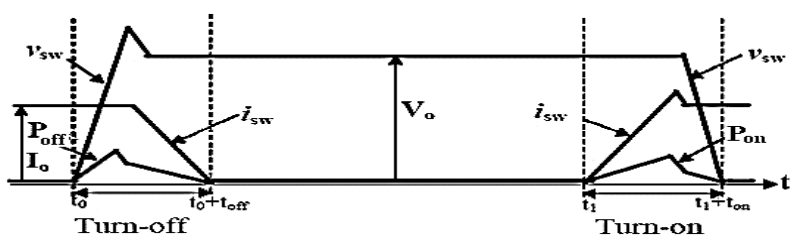

Fig. 6. Power loss during switching turn-on and turn-off due to overlap between switching currents $\left(I_{D S}\right)$ and switching voltages $\left(V_{D s}\right)$

The switching loss problem of the switching switching operation can be reduced by using soft-switching. The term soft-switching in power electronics refers to the various techniques in which switching transitions are made to be more gradual or not sudden. Switching losses decrease due to power dissipation when switching transitions take place there is no overlap between the voltage and current on the switching.

\section{Experimental Result}

System testing will be performed on each device to see the data characteristics generated by the equipment and to know, then to be tested as a whole with integrated.

\subsection{PV Test}

PV testing is performed to determine the characteristics of PV to sunlight that falls on the surface of PV. Testing of 810 WP PV characteristics is shown in figure 7 .

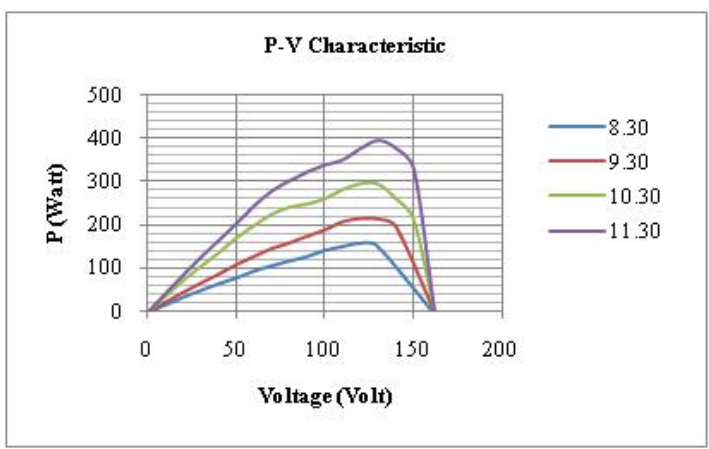

Fig. 7. PV characteristic

\subsection{DC-DC SEPIC ConverterTest}

This test is aimed to know the function of SEPIC converter as DC-DC converter which is used to increase and decrease voltage. The SEPIC converter test uses a modified resistive load but with a fixed input voltage of 
$100 \mathrm{~V}$ and the duty cycle is fixed at $60 \%$. This test is up to a nominal power of $1000 \mathrm{~W}$. Switching waveform shown in Figure 8 is the drain-source waveform MOSFET.

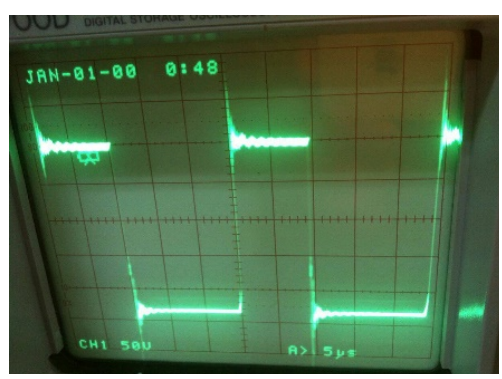

Fig. 8. Drain-Source Signal MOSFET duty cycle $60 \%$

The SEPIC converter test data is shown in Table 2.

Tabel 2. SEPIC Converter Testing

\begin{tabular}{|l|l|l|l|l|l|l|l|}
\hline \multicolumn{7}{|c|}{ SEPIC } \\
\hline $\begin{array}{l}\text { Duty } \\
\text { cycle }\end{array}$ & $\begin{array}{l}\text { Vin } \\
\text { (V) }\end{array}$ & $\begin{array}{l}\text { Iin } \\
\text { (A) }\end{array}$ & $\begin{array}{l}\text { Iout } \\
(\mathbf{A})\end{array}$ & $\begin{array}{l}\text { Vo } \\
\text { prak } \\
\text { (V) }\end{array}$ & $\begin{array}{l}\text { Vo } \\
\text { teori } \\
\text { (V) }\end{array}$ & $\begin{array}{l}\text { Error } \\
\mathbf{( \% )}\end{array}$ & $\begin{array}{l}\text { Effisiensi } \\
(\%)\end{array}$ \\
\hline \multirow{5}{*}{$60 \%$} & 100 & 10 & 5 & 160 & 150 & 6,67 & 80,0 \\
\cline { 2 - 8 } & 100 & 8 & 4,2 & 153 & 150 & 3,33 & 80,33 \\
\cline { 2 - 8 } & 100 & 5 & 3 & 138 & 150 & 8 & 82,8 \\
\cline { 2 - 8 } & 100 & 4,8 & 2,8 & 148 & 150 & 1,3333 & 86,33 \\
\cline { 2 - 8 } & 100 & 3,5 & 2 & 162 & 150 & 8 & 92,57 \\
\cline { 2 - 8 } & 100 & 2,6 & 1,4 & 149 & 150 & 0,6667 & 80,23 \\
\hline
\end{tabular}

From the test results seen the efficiency has been meet the design of the converter is $80 \%$ and the error voltage is not large ie error maximum $8 \%$. After performing converter testing, it is expected that the converter is able to work well when integrated with PV fluctuate to find the maximum power of $\mathrm{PV}$.

\subsection{Integration Test}

At the integration testing stage, the entire system is unified. Maximum Power Point Tracking Testing is integrated with SEPIC Converter as well as previously designed voltage and current sensors. The effect of MPPT P \& O on finding the maximum or peak power value of PV $810 \mathrm{WP}$, testing open loop and close loop. The test is carried out with resistive load at nominal power. In the first test of open loop testing or noncontrolled testing, the duty cycle of the SEPIC converter is maintained in all test conditions. While in the second test that is close loop testing or controlled testing, the duty cycle of SEPIC converter varies according to PV peak power condition in all test conditions.

From these tests, there will be differences in PV power output between controlled by soft-switching MPPT-SEPIC P \& O and without control. Table 3 and 4 show power output between controlled by soft-switching MPPT-SEPIC P \& O and without control. Collecting data between controlled and without MPPT control is done almost simultaneously at the same time and day. This is due to the PV characteristics that have rapid variable data changes, such as current values and PV voltages. This is to find the maximum power value when the solar panel is in a load state when using MPPT controls or not.

Table 3. Data Test Results system without MPPT control

\begin{tabular}{|l|l|l|l|l|l|}
\hline $\begin{array}{l}\text { Vin } \\
\text { V) }\end{array}$ & Iin (A) & Vo (V) & Io (A) & Po (W) & $\begin{array}{l}\text { Pin } \\
\text { (W) }\end{array}$ \\
\hline 144,9 & 1,4 & 145 & 0,9 & 130,5 & 202,86 \\
\hline 153,1 & 1,4 & 153,5 & 0,9 & 138,15 & 214,34 \\
\hline 146,7 & 1,4 & 147 & 1 & 147 & 205,38 \\
\hline 156,4 & 1,4 & 156,1 & 0,9 & 140,49 & 218,96 \\
\hline 150,1 & 1,4 & 159,3 & 0,92 & 146,556 & 210,14 \\
\hline 153 & 1,4 & 159,8 & 0,92 & 147,016 & 214,2 \\
\hline 156 & 1,4 & 158 & 0,92 & 145,36 & 218,4 \\
\hline 154 & 1,4 & 160,7 & 0,92 & 147,844 & 215,6 \\
\hline 155 & 1,4 & 158 & 0,92 & 145,36 & 217 \\
\hline 151 & 1,4 & 156 & 0,91 & 141,96 & 211,4 \\
\hline 150 & 1,4 & 156 & 0,92 & 143,52 & 210 \\
\hline 150 & 1,4 & 154 & 0,9 & 138,6 & 210 \\
\hline 141 & 1,4 & 143 & 0,87 & 124,41 & 197,4 \\
\hline 117 & 1,5 & 120 & 0,82 & 98,4 & 175,5 \\
\hline
\end{tabular}

Table 4. Data Test Results system with MPPT control

\begin{tabular}{|l|l|l|l|l|l|}
\hline $\begin{array}{l}\text { Vin } \\
(\mathrm{V})\end{array}$ & $\begin{array}{l}\text { Iin } \\
(\mathrm{A})\end{array}$ & Vo (V) & Io (A) & Po (W) & Pin (W) \\
\hline 120 & 1,8 & 135 & 0,83 & 112,05 & 216 \\
\hline 122 & 2,1 & 141 & 0,86 & 121,26 & 256,2 \\
\hline 130 & 2,3 & 153,2 & 0,85 & 130,22 & 299 \\
\hline 130 & 2,3 & 170 & 0,9 & 153 & 299 \\
\hline 130 & 2,6 & 172 & 0,93 & 159,96 & 338 \\
\hline 132 & 2,6 & 176 & 0,94 & 165,44 & 343,2 \\
\hline 141 & 2,8 & 176 & 0,94 & 165,44 & 401,1 \\
\hline 142 & 2,7 & 183 & 0,96 & 175,68 & 383,4 \\
\hline
\end{tabular}

From the system test results, it can be compared that the MPPT tracking results can be better than tracking when the converter duty cycle is made fixed under all conditions. This proves the program has been properly running and can find the maximum power of PV. The amount of MPPT power increase can be proportionalized in Table 5 Since the power when the duty cycle fix is $40 \%$ is very far from the other power, then that compares only MPPT P \& O power and 50\% duty cycle fix power to see the percentage of MPPT P \& O power increase. Figure 9 show graphic of comparation 
between SEPIC converter with control and without control.

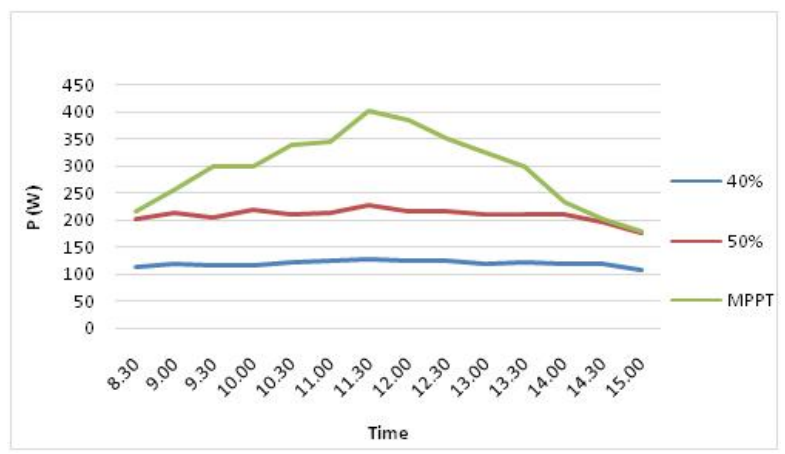

Fig. 9. comparation between SEPIC converter with control and without control.

Table 5. MPPT power increase

\begin{tabular}{|l|l|l|l|}
\hline $\begin{array}{l}\text { Time } \\
(+7 \mathrm{GMT})\end{array}$ & $\begin{array}{l}\text { P without } \\
\text { MPPT (W) }\end{array}$ & $\begin{array}{l}\text { P with } \\
\text { MPPT (W) }\end{array}$ & $\begin{array}{l}\text { Power } \\
\text { increase (\%) }\end{array}$ \\
\hline 8.30 & 202,86 & 216 & 6,083333 \\
\hline 9.00 & 214,34 & 256,2 & 16,3388 \\
\hline 9.30 & 205,38 & 299 & 31,31104 \\
\hline 10.00 & 218,96 & 299 & 26,76923 \\
\hline 10.30 & 210,14 & 338 & 37,8284 \\
\hline 11.00 & 214,2 & 343,2 & 37,58741 \\
\hline 11.30 & 228,4 & 401,1 & 44,68085 \\
\hline 12.00 & 215,6 & 383,4 & 43,7663 \\
\hline 12.30 & 217 & 350 & 38 \\
\hline 13.00 & 211,4 & 324,3 & 34,81344 \\
\hline 13.30 & 210 & 300 & 30 \\
\hline 14.00 & 210 & 234 & 10,25641 \\
\hline 14.30 & 197,4 & 204 & 3,235294 \\
\hline 15.00 & 175,5 & 180 & 2,5 \\
\hline Average power increase with MPPT & $\mathbf{3 1 , 9 8}$ \\
\hline
\end{tabular}

\section{Conclusion}

Soft-switching MPPT SEPIC converter using P \& O algorithm can increase the output power of PV. Based on experimental results that have been done, about $31.98 \%$. Although the method succeeded in tracking the power and able to raise the power to more than $30 \%$, but this power value is still far from the maximum power of PV that has a maximum power of $810 \mathrm{WP}$. Power that can be optimized using this method is only capable of a maximum of $401.1 \mathrm{~W}$ that is less than $50 \%$ of the maximum power of PV. There are many factors that influence, one of which is the physical state of PV is dirty, the existence of buildings that block the entry of light into the PV and the sensor is less precise in reading the data. So, for the future will be done optimization on it.

\section{References}

1. A. Tjahjono, O.A. Qudsi, N.A. Windarko, D.O. Anggriawan, A. Priyadi, M.H. Purnomo, Electrical Engineering and Informatics (MICEEI), 2014 Makassar International Conference on 14-19 (2014)

2. J. Ahmed and Z. Salam, IEEE Trans. on Sustainable Energy, 7, 506-1515 (2016)

3. M. Killi and S. Samanta, in IEEE Transactions on Industrial Electronics, 62, 5549-5559 (2015)

4. Ma, X. Zhou, Z. Gao and T. Bai, 2017 IEEE International Conference on Mechatronics and Automation (ICMA) (2017)

5. H. Wang, X. Jin, H. Zhao and Y. Yue, 2017 IEEE International Conference on Mechatronics and Automation (ICMA) (2017)

6. N. Kumar, I. Hussain, B. Singh and B. K. Panigrahi, IEEE Trans. on Energy Conversion, 32, 983-992 (2017)

7. N. Barua, A. Dutta, S. Chakma, A. Das and S. S. Chowdhury, 2016 IEEE International WIE Conference on Electrical and Computer Engineering (WIECON-ECE) (2016)

8. S. Mohanty, B. Subudhi and P. K. Ray, IEEE Trans. on Energy Conversion, 32, 340-347 (2017)

9. S. W. Lee and H. L. Do, IEEE Trans. on Industrial Electronics, PP

10. G. Tibola, E. Lemmen, J. L. Duarte and I. Barbi, IEEE Trans. on Power Electronics, 32, 9210-9222 (2017)

11. R. Moradpur, H. Ardi and A. Tavakoli, IEEE Trans. on Industrial Electronics, PP

12. H. L. Do, IEEE Trans. on Power Electronics, 27, 2879-2887 (2012)

13. C. L. Shen, Y. E. Wu and M. H. Chen, 2008 IEEE International Conference on Industrial Technology (2008)

14. A. M. Zacharias and T. R. Devaprakash, 2014 Annual International Conference on Emerging Research Areas: Magnetics, Machines and Drives (AICERA/iCMMD) (2014) 